\title{
MODELING BLACK STUDENT ACADEMIC PERFORMANCE IN HIGHER EDUCATION
}

\author{
A. Wade Smith and Walter R. Allen
}

\begin{abstract}
Recent research has noted differences in the predictive efficacy of educational attainment models produced for whites as opposed to blacks; and called for more resolution in the findings on blacks in advance of further comparative analyses. The National Study of Black College Students (NSBCS) is employed to develop a model that distinguishes between high- and low-performing black undergraduates attending public, four-year institutions. In the NSBCS sample $(N=695)$, discriminant function analysis identifies several institutional and student characteristics which are related to black students' educational outcomes. Specifically, students with both high occupational aspirations and high academic performances tend to be male, attend comparatively larger schools, and, to a lesser degree, be relatively well-adjusted upperclassmen. When academic performance is the sole issue, it is positively correlated with institutional quality, but the advantage belongs to black females. Contrary to the suggestions of previous research, black community sentiment did not have relationships with educational outcomes to the extent expected. These results suggest that future models of black educational attainment marry traditional Wisconsin-type measures with institutional and student attributes.
\end{abstract}

Since the advent of the Wisconsin model more than a decade ago, the process of status attainment has received increasing scrutiny. Researchers in sociology and education have attempted to both expand the repertoire of groups for whom the model applies (McClendon, 1976; Portes and Wilson, 1976) and to examine the specific nature of educational attainment per se, using the tenets of macrosocial status attainment (Porter, 1974; Sewell et al., 1970). To this point, the generalized model of status attainment first advanced by Blau and Duncan (1967) - on the basis of white Wisconsin males - has been found to articulate the process both similarly and dissimilarly for white males and females (Fligstein and Wolf, 1978; Spaeth, 1977;

An earlier version of this paper was presented at the 1983 meetings of the American Sociological Association, Detroit, Mich.

A. Wade Smith, Arizona State University; Walter R. Allen, University of Michigan.
Research in Higher Education
(c) Agathon Press, Inc.
Vol. 21, No. 2, 1984 
McClendon, 1976; Treiman and Terrell, 1975). Attempts to apply the model to nonwhites have been even more frustrating (Beilby, Hauser, and Featherman, 1977; Porter, 1974; Duncan, 1968).

The attention given to educational attainment as a special case of status attainment may be due in part to the findings of differential returns from the former accruing to whites and nonwhites, males and females. In addition, while racial differences in educational attainment are well-documented, there is little agreement regarding the reasons for their existence. After a review of more-recent salient research, Gottfredson (1981) reiterated that it is the outline of the process among blacks which is ambiguous and advised caution against further interracial comparisons until education within this group is better understood. Thus, the intent of this paper is to delineate those factors contributing most heavily to educational attainment among blacks.

\section{EDUCATIONAL ATTAINMENT IN THE WISCONSIN TRADITION}

The original Wisconsin model has benefitted from continued testing and refinement by other investigators, particularly regarding the efficiency with which the model approximates the educational attainment of various subpopulations. Essentially, the basic scenario depicts family background characteristics and ability as codeterminants of individual scholastic achievement. Then an individual's demography, ability, and achievement shape the views of significant others regarding the person's academic potential. These variables are said to combine to influence educational aspirations; and, finally, all preceding variables plus aspirations determine educational attainment.

Changes in the original model have evolved as a result of subsequent research. Not all of the family background variables (i.e., parental education and occupation, family income) have been demonstrated to be of equal importance. Mothers' educations and occupations were found to have different and more powerful effects than those of fathers, depending on the sex and race of the student (Treiman and Terrell, 1975; Porter, 1974; Sewell and Shah, 1968). Fathers' attainments are more often missing among black as opposed to white students, and there is some disagreement as to how this measurement error should be specified and remedied (Beilby et al., 1977; Bowels, 1972). The use of standardized tests as measures of ability (e.g., Jencks et al., 1972) has come under increasing attack. Intelligence and achievement test performance have been demonstrated to reflect cultural assimilation as well as economic advantage. In other words, beyond the majority culture, their utility as measuring devices of ability is suspect (Taylor, 1980). As a result, even some scholars trained in the tradition of the Wisconsin model have abandoned the use of standardized test measures (Hogan and Feather- 
man, 1977). Finally, the extent to which aspirations are clearly prior to performance varies depending upon the student's gender and race (Kerchoff and Campbell, 1977; Portes and Wilson, 1976; Sewell and Shah, 1968).

Among blacks, specific variations have been observed in the order and magnitude of some of the respondent characteristics called for by the model (Portes and Wilson, 1976) and the absence of effects from student's significant others (Wilson, 1979). Also, there has been a suggestion that, for blacks, the basic model might require modification to include measures of institutional characteristics - possibly acting on student attributes - in order to understand the black educational attainment process (Wilson, 1979; Kerchoff and Campbell, 1977). For the most part, the researchers cited above do seem to agree that educational attainment outcomes should be defined in terms of academic performance more than years in school.

\section{RESEARCH AGENDA}

In sum, a model of educational attainment among blacks should most likely employ mothers' education and occupation (since these are more often obtainable than fathers' characteristics), family income, and gender (because of previous findings of sex differences) as demographic variables. Logically, because family structure is such a large determinant of family income, especially among blacks, it too should be included. Some measure of ability other than a standardized test score is also desirable. Previous academic performance might well go far in explaining subsequent performance; but it would restrict the analysis to later years in the educational system.

The use of high-school performance characteristics to denote college level performance is one such application. In this type of research, the operationalization of descriptive features of the institution could employ fairly broad dimensions, especially in an exploratory effort such as this one. Because college attendance involves some degree of freedom of choice, institutions could easily be described according to milieu (location, size, etc.) or orientation (quality, undergraduate vs. graduate education, etc.). Furthermore, the student's attributes that might affect attainment would likely be those directly related to the student's position in the institutional environment (viz., residence, dependency status, alienation, time in the system, etc.). ${ }^{1}$ Finally, another advantage in focusing on higher education is that definitions of performance and aspirations are easily formulated. A straightforward measurement of a student's grades and occupational aspirations serves to operationalize educational attainment outcomes. With these considerations in mind, Figure 1 presents a heuristic model depicting the influence of four major blocks of variables on student outcomes.

Admittedly, any analysis of this model must be considered exploratory, 


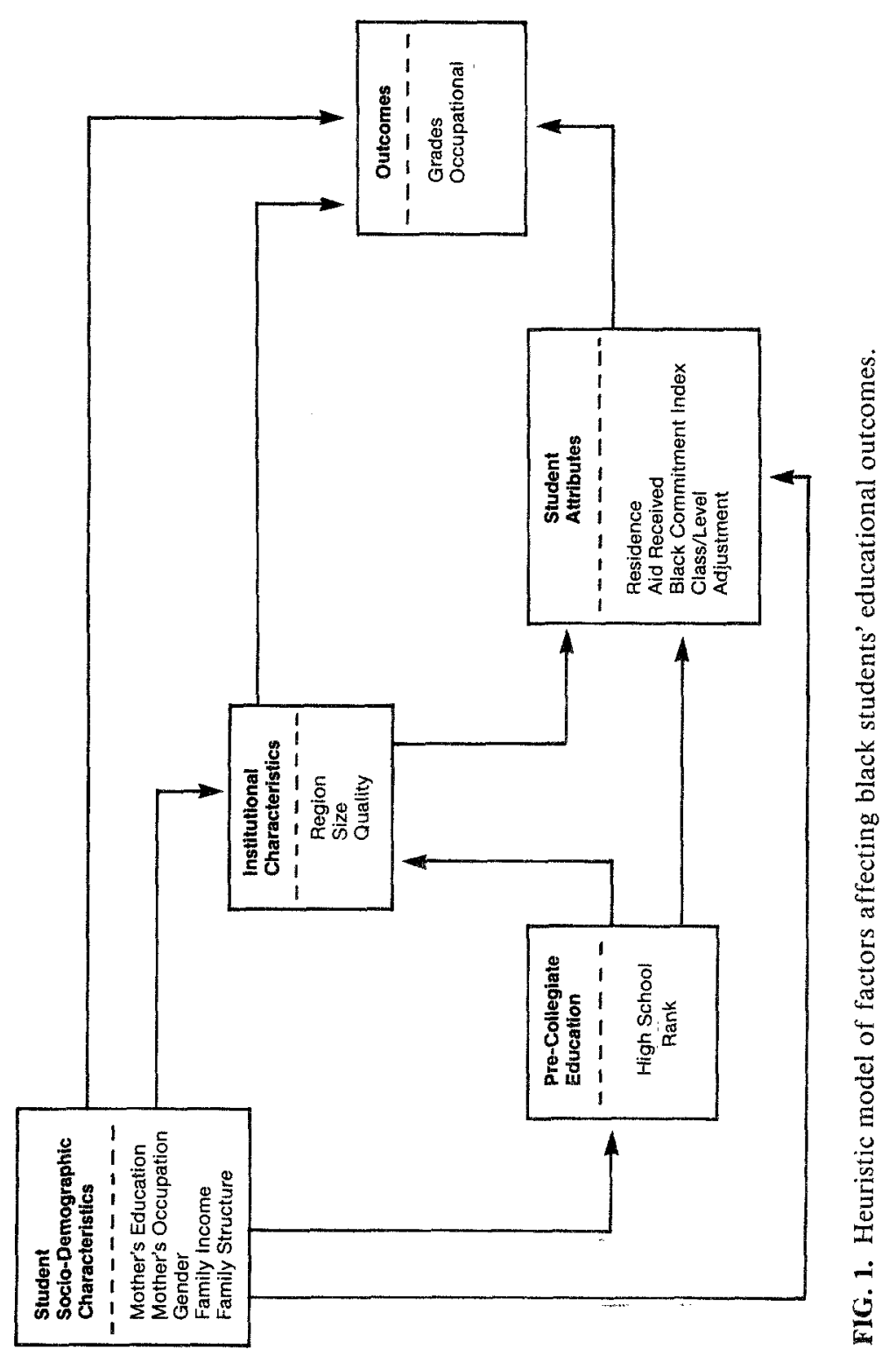


given the stage of the educational attainment process under investigation and the presence of previously untested variables about institutional and student attributes. Still, there are at least three basic research questions of interest here:

1. What are the relative contributions of the components of the model to black student outcomes?

2. Do background factors predominate, as in traditional status attainment models of white students?

3. Of the new blocks of variables, are institutional characteristics more important than student attributes?

Because this is a beginning effort, these issues are still somewhat intertwined. The basic thrust here is to describe the factors affecting black student achievement, then to discern whether the variables from the prior blocks (and previous research) have more influence than those from the more proximate blocks (added in this study). If so, then the traditional educational attainment model might well work for blacks, provided it was refined to include measures which specify the effects of sociodemographic characteristics on attainment.

However, if institutional and/or student attributes are significant in shaping black student achievement, then the questions for future research may turn more on whether lists of these new characteristics are exclusive, or even appropriate. Moreover, the possibility should be considered that researchers in educational attainment have been talking past one another. It may be the case that for black students, educational aspirations are best accounted for by background and ability factors while academic performance is more influenced by institutional and/or student characteristics; or vice-versa.

Of the attributes particular to black students, their racial identification or ideology (i.e., militancy) is of special interest here because of the extent to which this characteristic has figured prominently in previous research on black collegians. Gurin and Epps (1975) documented the existence of a very strong negative relationship between black militancy and educational outcomes among black collegiate cohorts of the late 1960s and early 1970s. For these black students, both their adjustment to campus life and their classroom performance were depressed by a high commitment to their racial identification. On the basis of this and other such evidence, Tinto (1975) placed black students' social and structural integration prominently among those factors directly affecting their (adjustment- and performance-based) attrition.

Since the data on which previous research based its findings of a strong and direct relationship between racial identification and attainment were obtained during a period of heightened racial militancy-especially on the part of black collegians - as well as from blacks attending predominantly 
black institutions, another of the contributions of this research is the investigation of whether this relationship is specific to that period/group. If a direct relationship between black students' racial ideology and their adjustment and performance is found to exist among a more contemporary sample drawn from predominantly white institutions, then the earlier findings would be generalizable beyond the restricted sample upon which they were based. The absence of such a relationship here would lead to questions of whether the racial ideology-attainment relationship previously found among black collegians was specific to predominantly black institutions, or to the late 1960 s, or both.

\section{DATA AND METHODS}

\section{The Data}

The National Study of Black College Students (NSBCS) is employed to address these issues. NSBCS data were collected from 695 black undergraduate students via a mailed questionnaire in the Spring of 1981. All respondents attended four-year predominantly white public institutions. Nationwide, the number of black students at such schools is estimated to have been 392,484 in 1980 (Smith, 1980). The present sample consists of $27 \%$ of the total black student population attending six four-year predominantly white public colleges and universities. But because each of the six institutions represents a cluster of schools with similar educational missions, student body sizes, and proportions of black students, the NSBCS data have a sampling error of less than $5 \%$ for the national black student population at these types of schools (Blalock, 1972). Obviously, having less than $100 \%$ response rate from each of these schools results in a reduced sample size and potentially lowers the cell sizes or case-base involved in any cross-classifications, especially when numerous variables are involved. ${ }^{2}$

For this analysis, the multicategorical or interval responses for many variables have been reduced to either dichotomies or trichotomies because in some cases their distribution was not normal, or because some of the independent variables naturally occur at nominal or ordinal levels. For these reasons, mothers' years of education were recorded (0-11 years, high school graduates, $13+$ years/some college) as were mothers' occupations (blue collar vs. white collar). Family income was collapsed (low vs. high) using $\$ 20,000$ as the dividing line. The distinction in family types is between nuclear families and other structures. Students' high school achievement was measured by relative percentage ranking in their graduating class ${ }^{3}$ and dichotomized as top $10 \%$ or lower. The characteristics of the institutions were categorized according to: region (south, west, north), size (large vs. small), and academic quality (highest, higher, and high). ${ }^{4}$ 
The student attributes, indicating position in the campus structure, are: residence (on-vs. off-campus), financial aid received (low vs. high), and class/level (first year, sophomore, junior, senior). The NSBCS also indexes a black student's nationalist ideology - commitment to the black community (low vs. high) - using three questions. Students were asked to respond, on a four-point scale from Strongly Agree to Strongly Disagree, to the following statements:

1. There is a need for a black political party.

2. Interracial dating and marriage are equally acceptable to within-race dating and marriage. ${ }^{5}$

3. Schools with a majority of black student populations should have a majority of black teachers and administrators.

This analysis includes the additional psychological attribute of a student's self-perception of adjustment to campus life. The responses to the question, "How much do you, as a black student, feel a part of general campus life, insofar as student activities and government are concerned?" ranged from "not at all" to "considerable" and were dichotomized into low vs. high categories.

The outcomes of the collegiate educational process are measured using the students' self-reported grades and occupational aspirations. Since there is no universally available measure of undergraduate performance (e.g., a standardized achievement test administered to all undergraduates), the NSBCS queries students as to their current grade point average (GPA). Here, students' GPAs are divided between those B and above (high) and those less than B (low)-on the grounds that a cumulative 3.0 average significantly enhances a student's potential for admission to a quality graduate or professional school. In recognition of the previous research which demonstrated students' occupational aspirations (Asp) influence on academic performance, and to be subject to influences from the same, a dichotomized (low/ high) measure of that outcome is included as well.

For all variables, the initial (lowest) category is coded 1, with subsequent categories coded $2,3 \ldots$. etc. The descriptive statistics for all exogenous variables appear in Table 1.

\section{Methods and Procedures}

The development and dissemination of the Wisconsin model, noted in the literature review, has also resulted in the identification of path analysis as the methodology most often associated with the study of status attainment. Understandably, previous attempts to replicate the fit of Blau and Duncan's (1967) model on females and nonwhites have employed similar methodo- 
TABLE 1. Means and Standard Deviations for Demographic and Institutional Variables $^{a}$ : National Study of Black College Students $(N=695)$

\begin{tabular}{lrrr}
\hline Variable & M & \multicolumn{1}{c}{ SD } & $N^{b}$ \\
\hline Mother's education & 4.07 & 1.14 & 659 \\
Mother's occupation & 387.46 & 246.31 & 607 \\
Student's gender & 1.65 & .48 & 695 \\
Family income & 6.01 & 3.72 & 629 \\
Family structure & 6.71 & 3.29 & 691 \\
Student's high school rank & 3.78 & 2.00 & 671 \\
Region of institution & 2.09 & 1.78 & 695 \\
Size of institution & 1.52 & .50 & 695 \\
Institutional quality & 1.80 & .81 & 695 \\
Student's residence & 5.01 & 2.41 & 691 \\
Financial aid received & 3.90 & 1.99 & 674 \\
Black commitment index & 6.44 & 2.88 & 658 \\
Class/level & 2.48 & 1.14 & 684 \\
Student's adjustment & 2.26 & .85 & 684 \\
\hline
\end{tabular}

a See text for definitions and ranges.

${ }^{b}$ Total sample $N=695$.

logical techniques, although with less success. Furthermore, as applications of the basic status attainment framework have been extended to more circumscribed demographic groups (students) and employed more restrictive definitions of attainment (grades), the results have become even less consistent (Gottfredson, 1981).

Path analysis methods have three drawbacks that increasingly affect their utility in educational attainment research. First, as the variables that define attainment become less interval - and more likely to exist in blocks instead of as singular, definitive measures - the basic assumptions of regression analysis are often violated. Second, as more exogenous variables are added in attempts to discern those factors which may differentially affect attainment for other than white males, the list of findings lengthens, the debate over the causal order of the independent variables detracts from discussion of the central findings, and more assumptions are employed to control for the effects of clearly prior variables on subsequent ones. Since many variables of interest in this regard exist only at nominal or ordinal levels, the use of dummy variables lengthens the discussion, often without concomitant increases in the clarity of results. Third, the case base of some population subgroups is often not large enough in many data sets to support meaningful interpretations of findings generated using path analysis methods (Gottfredson, 1981). All three of these drawbacks are not always present in previous research, but most often at least one is salient. 
This analysis employs discriminant function analysis instead of path analysis. Briefly, the procedure weights and linearly combines a set of characteristics on which groups are expected to differ. The discriminating variables are weighted and combined into an exclusive set, so as to statistically maximize the differences between the groups (Klecka, 1980). ${ }^{6}$ This method provides a parsimonious set of results, and one which clearly orders the factors influencing the attainment of black students in white schools. Further, the relevant factors will be associated with that part of student outcomes (grades or aspirations) with which they have the greatest relationship. ${ }^{7}$ Finally, since the heuristic model (Figure 1) shows all prior variables to have direct effects on attainment, as well as indirect effects via all subsequent variables, the existence of the relationships themselves is only one initial question. What is ultimately of interest is which variables have the greatest influences net of all other variables, and on which type of outcomes? Discriminant analysis speaks directly to these issues. ${ }^{8}$

\section{THE FINDINGS}

The functions presented in Table 2 relate students' sociodemographic, institutional, and personal attributes to academic outcomes. Both functions are statistically significant $(p<.05)$, but they are clearly not equal in the extent to which they distinguish among the dependent variables. While the variables in the heuristic model account for $27.5 \%$ of the variance in black student attainment, as combined in Function I they account for more than three-fourths of the variance explained $(27.5 \% \times 77.24 \%=21.2 \%)$. As formed in Function II, they depict less than $4 \%$ of the variance in black students' academic outcomes.

The first function differentiates black students with both high aspirations and high academic performance from all others. The predominant factors here are gender and the size of the student's university, followed by their class level and adjustment. Males are more likely than females to have both high aspirations and good grades. Similarly, the larger the university the more likely are black students to manifest good grades in addition to high aspirations. Black high aspirants and achievers tend to be in the upper division and/or more comfortable on campus. To a lesser extent, black students who attend flagship institutions, who did relatively better in high school, and whose mothers have relatively more education are also likely to have both high aspirations and high grade-point averages. Finally, non-Southern, dormitory-dwelling black students, and those on financial aid, exhibit some increased tendency over all others to fall into the high-performing/highaspiring group.

The second function serves to discriminate black collegians more system- 
TABLE 2. Discriminant Function Analysis for Demographic and Institutional Effects on Black Student Performance and Post-Graduate Aspirations

\begin{tabular}{lcr}
\hline & \multicolumn{2}{c}{ Standardized Coefficients } \\
\cline { 2 - 3 } Independent Variables & Function $\mathrm{I}^{*}$ & Function II* \\
\hline Mother's education & .21 & -.09 \\
Mother's occupation & -.00 & .00 \\
Student's gender & -.57 & .41 \\
Family income & .05 & .05 \\
Family structure & -.01 & -.02 \\
Student's high school rank & .22 & .08 \\
Region of institution & .14 & -.10 \\
Size of institution & -.52 & -.08 \\
Institutional quality & .25 & -1.31 \\
Student's residence & .13 & -.08 \\
Financial aid received & .15 & -.07 \\
Black commitment index & -.08 & -.13 \\
Class/level & -.31 & -.17 \\
Student's adjustment & .31 & -.03 \\
& & \\
\% Variance & $77.24 \%$ & $13.54 \%$ \\
Multivariate Centroids & & \\
Low asp/low GPA & & 2.34 \\
High asp/low GPA & 1.19 & 2.03 \\
Low asp/high GPA & 1.18 & 2.45 \\
High asp/high GPA & 1.36 & 2.56 \\
\hline
\end{tabular}

${ }^{*} P<.05$.

atically on the basis of academic performance. Here, students' grade point averages are associated foremost with institutional quality; while a student's gender, class level, and score on the black commitment index also exhibit connections with classroom performances. First, these data show that black students perform better at flagship institutions within state university systems. Second, all other things being equal, black females generally outperform black males in the classroom. Third, the relationship between class standing and black students' GPAs are surprisingly negative. Finally, high scores on the black commitment index are somewhat associated with lower academic performance.

The finding (in Function I) that a black student's relatively high rank in his/her high-school graduating class is associated with both high aspirations and a relatively better academic record in college deserves some immediate discussion. First, a comparatively good academic record in high school is 
likely to increase the quality of the institution of any student's collegiate destination. Second, Function II shows that institutional quality is positively related to black student performance. Black students at the research-oriented flagship institutions of state university systems have relatively higher GPAs than their cohorts at less prestigious schools; perhaps because the former are educated in a milieu where the "gentleman's B" is the norm, while the latter compete for what may be the "gentleman's C."

\section{SUMMARY AND DISCUSSION}

This paper set out to discern factors that offer significant contributions toward understanding black student educational attainment in college. Using the National Study of Black College Students, the analysis employed data containing aspects of the traditional model of educational attainment formulated in the Blau-Duncan tradition, and added blocks of variables focused on institutional and student differences thought to influence blacks' educational performances. These results suggest that in order to better understand the educational outcomes of black collegians, it might be productive to marry tenets of the well-known Wisconsin model with different parameters suggested by this and other research.

But before the discussion can go forward, a summary and assessment of the findings relative to the basic research questions is in order. In the first instance, not all of the components of even a modified Wisconsin model contribute both meaningfully and consistently to explanations of black postsecondary performance. Of the sociodemographic variables, only gender makes a meaningful difference; and even then, its direct relationships are not consistent. The institutional characteristic shown to be consistently salient is school quality. Institutional size has a large direct effect in distinguishing between high aspiring and high performing black students and all others, but none in strictly separating high- from low-achieving blacks; while regional location of the school has minimal impact in both cases. The impact of student attributes on outcomes also depends on the outcome of interest. Overall, mother's occupation, and family structure and income are of little help in describing the black collegiate outcomes of interest here.

While the family background variables of black students fail to predominate as they do in traditional educational attainment models for whites, ability retains a prominent place in any final model attempting to account for differences in career aspirations. However, institutional and student characteristics operate differently, depending on which outcome is the focus of attention. Even though separately the institutional variables have no direct association with black student aspirations per se, the combination of institutional size, quality, and region is associated with the difference between both 
high aspiring and high-performing black students, and all others.

However, when academic background is specifically the outcome of interest, its relationship to school quality dominates its association with all other institutional, student, and background characteristics. Student attributes produce mixed results. Campus residence and receipt of financial aid are associated with black students' having both high aspirations and good grades, but neither aid received nor residence is directly connected to grades per se. The racial ideology of black students does singularly impact attainment, but high commitment is not as devastating to academic success as expected on the basis of previous research. (More on this below.) Black students' class levels have a positive association when performance is coupled with aspirations, and a negative correlation when it is not. Finally, while those blacks having both high aspirations and performance are better adjusted to campus life, that relationship does not hold when performance is the sole issue. In sum, while the performances of black collegians are generally unrelated to sociodemographic factors, and sometimes to ability, they are heavily - if inconsistently - influenced by institutional and other student characteristics.

In the midst of these inconsistencies, the intensity of black students' racial identification deserves attention in a different respect. Its depressing relationship to academic performance could be surmised to be the result of either minority students' ideological conflicts with course content, or as lack of course selections relevant to their black experiences. Regardless, these results raise the question as to whether the relatively small correlations between performance and racial militancy found here differ from their substantial associations in previous research because of the differences in survey population, period in question, or both. If the lowered salience of racial identification exists within both predominantly black and predominantly white institutions, then obviously there is some period effect in operation. However, if more contemporary data show black students' racial ideologies to have more dramatic associations with outcomes in black as opposed to white institutions, then there is probably less homogeneity within the population of black students than has been acknowledged in previous research. ${ }^{9}$ In the final analysis, if intense racial identification has more negative impact on academic performance at mostly black than at predominantly white institutions, then black students' academic attainments may only reflect the extent of their acculturation.

What is clear from these findings is that the characteristics of higher educational institutions are associated with the academic performances of their black students. It is possible that elite public universities have some structural components which are associated with the classroom performances of black students, and which are unavailable on the campuses of lower quality 
institutions. If so, then what are these qualities; and are they transferable to nonelite public universities? Or, is there something embedded within the character of the highest quality institutions which justifiably enhances black student performance? Whichever scenario is more appropriate, undergraduate educators should no longer ignore the connection between the internal organs and/or operating procedures of their institutions and the resultant influences on black students' academic performances.

The implications of these results for comparative models of educational attainment per se, and status attainment in general, are no less clear. The findings here indicate that there is something about the organization and operation of educational institutions which is differentially related to the academic achievement of black students. Since educational attainment models have long existed as derivatives of generalized status attainment models, perhaps now a renewal of that relationship is in order - with an eye toward repayment. If educational attainment research can determine how and which structural characteristics of schooling institutions are associated with differences in the outcomes for blacks (and possibly others), then perhaps inferences can be carried over to the study of generalized status attainment.

Acknowledgments. This research was supported by grants from the Ford, Mott, and Spencer Foundations. We are thankful for the helpful comments of Mary Benin, Gary Flemming, and Max Heirich. Karen Wilson and June Meitz provided computational and editorial assistance. Nevertheless, the responsibility for all findings, interpretations, and errors, is ours.

\section{NOTES}

1. This list of variables indicative of institutional and student characteristics is not intended to be exclusive. One can easily think of other variables which might affect black student performance in particular (viz., size of the black student population, black/white student ratio, point of matriculation, and types of extracurricular activity). To keep this investigation within manageable proportions, these and other variables should be considered as possibilities for future research efforts.

2. Actually, the potential for bias is somewhat overstated, given that many of the "nonresponses" in the NSBCS data are due to the misclassification of other students as black Americans by their post-secondary institutions. Since very few blacks are misclassified as anyone else, and since all of the institutions in this sample appear equally as competent in this regard, any resulting sampling bias is very likely a statistical constant - which would add little to the total survey error given the extensive coverage of the target population (Kish, 1965).

3. Scholastic achievement is measured via performance in high school as opposed to a standardized test because (among other things) not all the universities sampled required the same test for admission. Relative, rather than absolute, rank is employed so as to similarly classify students from large and small high-school graduating classes.

4. Census definitions were used to categorize schools as either West (Pacific and Mountain), 
or South (East and West South Central, South Atlantic), with all others regarded as North. This formulation of region is necessary because of the preponderance of blacks in Southern

- four-year public institutions (Mingle, 1981). The size of the student body which distinguishes large and small schools is a 25,000 total student population. A graduate, research-oriented, and flagship institution in a state's university systern was designated to be of the highest caliber. A research- and graduate-oriented, but not a flagship school was considered of higher quality than a state university without a research tradition (e.g., one who's historical mission was training undergraduates, or "teacher training").

5. To make this question consistent with the others, the numerical value of the response scale was reversed.

6. Purists may question whether the NSBCS data, as construed here, violate the assumptions of multivariate normal distributions and/or equal group covariance matrices. They do not. The F-test for equality of covariances equals 75 . Further, Klecka (1980) and others advise that these conditions are of greatest importance when dealing with a small sample (Bibb and Roncek, 1976; Huberty, 1975). The 695 cases in the NSBCS dataset offer greater latitude in the rigor with which these assumptions are held. Moreover, the percentage of correct classifications here is $51.8 \%$ (or $35.8 \%$ better than chance; given the unequal sizes of the groups). This indicates that any violation of assumptions is not very harmful-although, as always, caution should be used in interpreting the results - and that efforts to use alternative formulations or otherwise improve on the data will have only marginal effects on the quality of results (Klecka, 1980, p. 62).

7. The original Wisconsin model demonstrated the existence of a nonrecursive relationship between aspirations and attainment. Rather than risking error in the arbitrary declaration of a causal order for the sake of replicating previous methodologies, the choice here is to allow the joint dimensionality of the educational outcomes and to use the analytical technique most appropriate for this dependent variable arrangement. Given the other advantages listed above, the loss of direct comparisons with previous statistical outcomes is a small price to pay for the capture of aspirations and attainment in a form more like the one implied by Sewell et al. (1970) and Sewell and Shah (1968).

8. In the path analysis, Wisconsin-type model tradition, the heuristic model (Figure 1) posits that the relationships between independent and dependent variables exist in a definitive temporal order, indicative of causality. The discussion to follow focuses on the correlational connections between independent and dependent variables because that is all that the statistical operations will allow. However, readers are reminded that in the cases of the sociodemographic, ability, and institutional variables the temporal relationships between these independent variables and the dependent variables are definitive.

9. Investigating these issues necessarily requires the simultaneous collection of data from blacks attending both predominantly white and predominantly black institutions. Future NSBCS data collection efforts will sample both black and white public universities.

\section{REFERENCES}

Beilby, W. T., Hauser, R. M., and Featherman, D. L. Response errors of black and nonblack males in models of intergenerational transmission of socioeconomic status. American Journal of Sociology, 1977, 82, 1242-1288.

Bibb, R., and Roncek, D. W. Investigating group differences: an explication of the sociological potential of discriminant analysis. Sociological Methods and Research, $1976,4,349-379$.

Blalock, H. N., Jr. Social Statistics (2nd ed.). New York: McGraw-Hill, 1972. 
Blau, P., and Duncan, O. D. The American Occupational Structure. New York: Wiley, 1967.

Bowels, S. Schooling and inequality from generation to generation. Journal of Political Economy, 1972, 80, S219-S251.

Duncan, $O$. D. Inheritance of poverty or inheritance of race? In D. P. Moynihan (Ed.). On Understanding Poverty: Perspectives from the Social Sciences. New York: Basic Books, 1968, 85-110.

Fligstein, N., and Wolf, W. C. Sex similarities in occupational status attainment: are the results due to the restriction of the sample to employed women? Social Science Research, 1978, 7, 197-212.

Gottfredson, D. C. Black-white differences in the educational attainment process: what have we learned? American Sociological Review, 1981, 46, 558-572.

Gurin, P., and Epps, E. G. Black Conciousness, Indentity, and Achievement. New York: Wiley, 1975.

Hogan, D. P., and Featherman, D. L. Racial stratification and socioeconomic change in the American North and South. American Journal of Sociology, 1977, $83,100-126$.

Huberty, C. J. Discriminant analysis. Review of Educational Research, 1975, 45, 543-598.

Jencks, C., et al. Inequality: A Reassessment of the Effect of Family and Schooling in America. New York: Basic Books, 1972.

Kerchoff, A. C., and Campbell, R. T. Black-white differences in the educational attainment process. Sociology of Education, 1977, 50, 15-27.

Kish, L. Survey Sampling. New York: Wiley, 1965.

Klecka, W. R. Discriminant Analysis. Beverly Hills, CA: Sage, 1980.

McClendon, M. J. The occupational status attainment process of males and females. American Sociological Review, 1976, 41, 52-64.

Mingle, J. R. The opening of white colleges and universities to black students. In Gail C. Thomas (Ed.). Black Students in Higher Education. Westport, Conn.: Greenwood, 1981, 18-29.

Porter, J. N. Race, socialization, and mobility in educational and early occupational attainment. American Sociological Review, 1974, 39, 303-316.

Portes, A., and Wilson, K. L. Black-white differences in educational attainment. American Sociological Review, 1976, 41, 414-431.

Sewell, W., and Shah, V. P. Parent's education and children's educational aspirations and achievements. American Sociological Review, 1968, 33, 191-209.

Sewell, W., Haller, A. O., and Ohlendorf, G. W. The educational and early occupational attainment process: replication and revision. American Sociological Review, $1970,35,1014-1027$.

Spaeth, J. Differences in the occupational achievement process between male and female college graduates. Sociology of Education, 1977, 50, 206-217.

Smith, D. H. Admissions and Attrition Problems of Black Students at Seven Predominantly White Universities. Washington, D.C.: National Advisory Committee on Black Higher Education and Black Colleges and Universities, 1980.

Taylor, H. F. The I.Q. Game: A Methodological Inquiry into the Heredity-Environment Controversy. New Brunswick, N.J.: Rutgers University Press, 1980. 
Tinto, V. Dropout from higher education: a theoretical synthesis of recent research. Review of Educational Research, 1975, 45, 89-125.

Treiman, D. J., and Terrell, K. Sex and the process of status attainment: a comparison of working men and women. American Sociological Review, 1975, 40, 174200.

Wilson, K. L. The effects of integration and class on black educational attainment. Sociology of Education, 1975, 85, 84-97.

Received April 3, 1984 